\title{
Structural Evolution and Properties of Hot Rolled Steel Alloys
}

\section{*Akpan, Emmanuel Isaac and Haruna, Idoko Andrew}

Department of Materials and Production EngineeringAmbrose Alli University, Ekpoma, Edo

$$
\text { State, Nigeria }
$$

*Corresponding Author: emma_eia@yahoo.com

\begin{abstract}
Microstructural evolution during hot rolling of mild steel $(0.3 \% \mathrm{C})$ has been considered to determine its relationship with the mechanical properties. Strain, strain rate, temperature and Zener Hollomon parameter were considered as structural parameters. Deformation parameters were collected industrially and the Zener Hollomon parameter calculated from the formula; $Z=\dot{\varepsilon} \exp \left(\frac{Q}{R T}\right)$. Microstructural features considered were grain size, inclusions, distribution of phases and banding. The grain size was calculated using the ASTM grain size number and the fraction distribution of phases was determined using a $10 \times 10$ grid counting. Mechanical properties considered were ductility, tensile strength, hardness and yield strength determined by laboratory experiments. Grain size was found to be inversely related to the Zener Hollomon parameter. Strength (Tensile, Yield and Fracture) were found to be inversely related to grain size but directly related to fraction distribution of phases. Banded structure and inclusions were found to be detrimental to strength and ductility.
\end{abstract}

Keywords: Recrystallization, Microstructure, Zener Hollomon Parameter, Deformation, Rolling, mild steel 


\section{INTRODUCTION}

The rolling process is one of the most popular processes in manufacturing industries, such that almost80 percent of metallic equipment has been exposed to rolling at least one time in their production period [1].Improving the hot rod mill process in Nigeria is mandatory for the steel industry owing to the increasingly severe specifications being imposed by end users. Within this objective a good knowledge of structural evolution during hot rolling and its relationship with the resulting properties of the final product becomes of great importance. This resulting relationship could provide useful information for process control and optimization, reducing the need of costly on-line experimentation.

During hot deformation the average dislocation density of the material increases several orders of magnitude. Two metallurgical processes become active to reduce the dislocation excess: recovery and recrystallization. In austenite, the later is the most important restoration process. Depending on temperature, strain and strain rate, the recrystallization could begin during deformation (dynamic recrystallization) or in the interpass time (static recrystallization) [1, 2]. In order to describe the microstructural evolution, a description of the recrystallization progress and the resulting austenite grain size. The relationship between microstructure of low carbon steel and properties has been studied using parametric methods by some authors [1-8].

The aim of this work is to establish a relationship between the evolving structure and the resulting properties of hot rolled steel materials. It covers the development of microstructure during hot rolling schedule considering the effect of structural parameters (strain, strain rate, temperature, Zener Hollomon parameter and grain size) and its relationship with the resulting properties.

\section{METHODOLOGY}

\subsection{Hot Rolling Process Study}

A process study was conducted on the hot rolling plant of the Universal Steel Limited in order to determine the various parameters that may affect the properties of the steel along the rolling sequence. The rolling sequence is shown in Figure 1 
Remelting operation:An electric arc furnace is used in the remelting of scraps with addition of some ferroalloys for to regulate the composition of the resulting steel. The molten metal is then casted into billets $(1400 \mathrm{~mm} \times 100 \mathrm{~mm} \times 100 \mathrm{~mm})$ via continous casting process.

Reheating Operation: A $20^{\text {th }}$ Continuous Heat Furnace is used in reheating the billets before they are passed into the rolls for the rolling operation. The furnace has two compartments: the heating zone and the soaking zone. The billets are first stacked in the heating zone where the temperature is raised to $1100^{\circ} \mathrm{C}$ before being passed into the soaking zone where the temperature is raised to about $1250^{\circ} \mathrm{C}$ and allowed to stand for some time before being passed into the rolls.

Hot Rolling Operation: During the rolling operation the billet is passed into the roughening mill (3 high mill 2- stand) which roughens the billet in six passes then deliver it to the intermediate tandem mill (2 high 4- stand) which gives the material successive smooth reduction in single passes. The material is then passed into the finishing mill (2 high 2-stand) which gives the final product a grooved shape.

\section{$20^{\text {th }}$ Continuous}

Heat Furnace 3 High mills
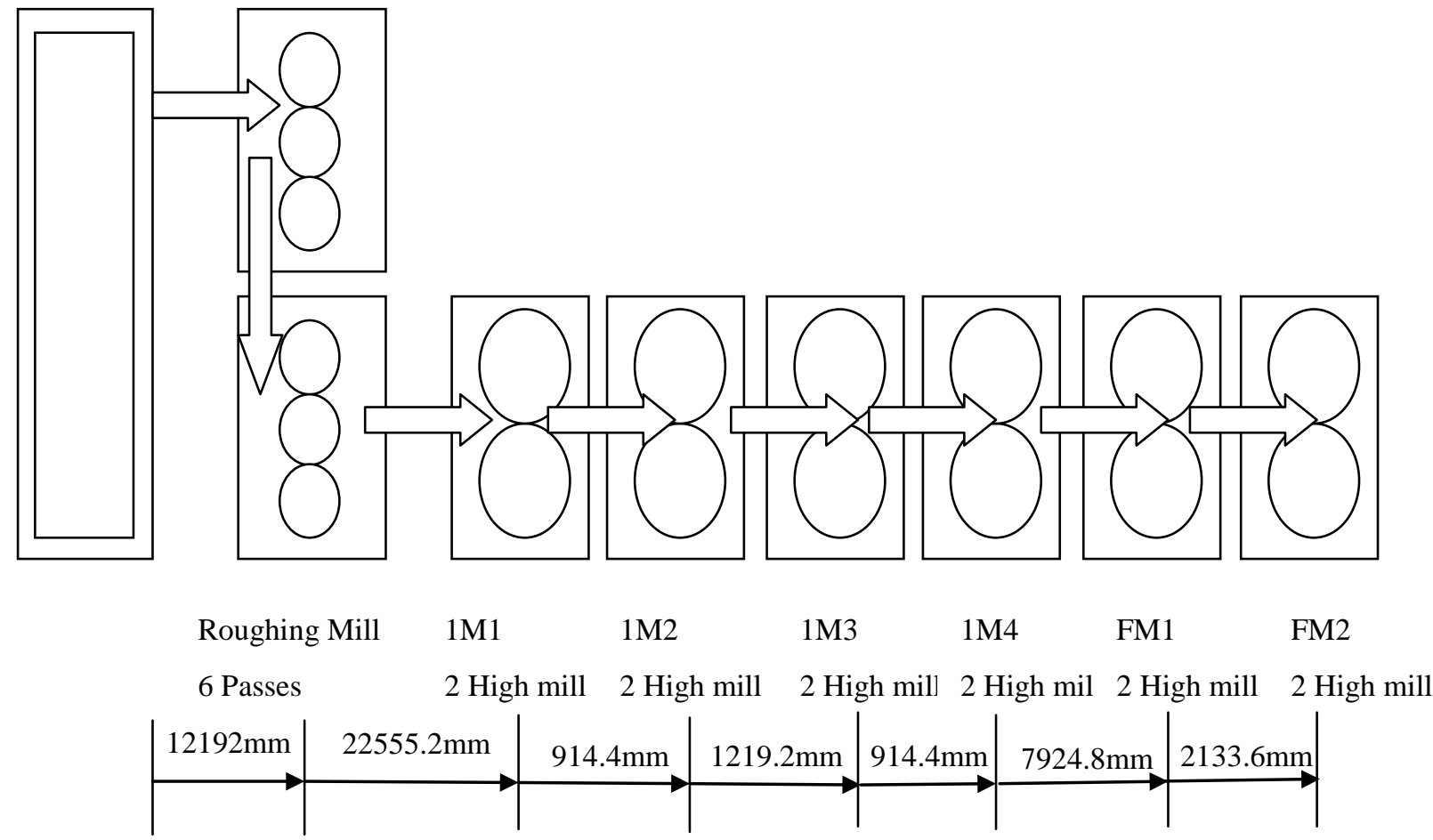

Figure 1: Steel Hot Rolling Sequence of Universal Steel Limited 


\subsection{Materials}

Mild steel samples of composition C(0.3081), $\mathrm{Si}(0.3699), \mathrm{S}(0.0929), \mathrm{Ni}(0.0973), \mathrm{Mn}(0.9635)$ $\mathrm{Cr}(0.1531), \mathrm{Cu}(0.2706), \mathrm{Sn}(0.0165), \mathrm{Pb}(0.00061)$ and $\mathrm{Fe}(97.64)$ were received from Universal Steel company in three batches from the three operational points along the rolling sequence for the study which were then subjected to mechanical and metallographic testing to determine its properties . The samples were designated; as cast, roughened and finished product.

\subsection{Mechanical Testing}

The mechanical tests considered were tensile and Hardness test. The tensile test was carried out in the Department of Metallurgical and Materials Engineering, Federal University of Technology, Owerri using a Monsanto Tensometer [type w, serial 11148]. The result obtained was then used to deduce; Ductility, Yield Strength, Ultimate Tensile Strength and the Fracture Strength of the samples. The hardness test was conducted in National Metallurgical Training Institute, Onitsha, Anambra State, Nigeria using Hann and Klob Rockwell hardness tester (scale c, RHC).

\subsection{Metallography}

The metallography test was conducted in TCR Engineering Services Ltd PVT India with a Metallurgical Microscope.

\section{RESULT AND DISCUSSION}

Table1: Summary of Hot Rolling Parameters

\begin{tabular}{l|lllll}
\hline No of Passes & $\begin{array}{l}\text { Input } \\
\text { Gauge }(\mathrm{mm})\end{array}$ & $\begin{array}{l}\text { Exit } \\
\text { Gauge }(\mathrm{mm})\end{array}$ & $\begin{array}{l}\text { Mill } \\
\text { speed(m/min) }\end{array}$ & $\begin{array}{l}\text { Reduction } \\
\%\end{array}$ & Temperature ${ }^{\circ} \mathrm{C}$ \\
\hline 1. & 100 & 90.0 & 12.4 & 10.0 & 1041.0 \\
2. & 90.0 & 65.0 & 12.4 & 27.7 & 1035.0 \\
3. & 65.0 & 60.0 & 12.4 & 8.0 & 1004.0 \\
4. & 60.0 & 50.0 & 12.4 & 16.7 & 995.0 \\
5. & 50.0 & 40.0 & 12.4 & 20.0 & 977.0 \\
6. & 40.0 & 20.0 & 12.4 & 50.0 & 966.0 \\
7. & 20.0 & 18.0 & 11.8 & 10.0 & 946.0 \\
8. & 18.0 & 16.5 & 11.8 & 8.0 & 934.0 \\
9. & 16.5 & 15.0 & 10.8 & 9.0 & 921.0 \\
10. & 15.0 & 13.6 & 10.8 & 9.0 & 918.0 \\
\hline
\end{tabular}




\begin{tabular}{l|lllll}
\hline 11. & 13.6 & 12.4 & 17.92 & 9.0 & 910.0 \\
12. & 12.4 & 11.0 & 19.74 & 11.0 & 891.0 \\
\hline
\end{tabular}

\subsection{Microstructure Evolution}

Figures 2-4 shows the microstructure of the cast material, roughened and finished product in double magnification (100 and 500) respectively.

The cast structure shows a non uniform distribution of ferrite and pearlite (Dark) structure with Widmanstaten ferrite shown at few regions. The grains are large and depict a structure that has not been deformed with an average ASTM grain size of 5.5.

Figure 3 reveals the effect of the initial 6 passes roughening on the structure of the intermediate material. Fine grained ferrite and pearlite are shown, indicating the breaking down of the initial structure during those passes. Deformation bands are observed along the rolling direction showing incomplete recrystallization. This indicates that the amount of deformation was large such that recrystallization at that temperature of rolling could not totally eliminate the deformation bands. Widmanstaten ferrite structure still remains but this time broken down and stretched in the rolling direction. This implies that the presence of Widmanstaten structure cannot be eliminated by large deformation and recrystallization. A few inclusions are also observed in the microstructure which was not observed in the cast material. This could be attributed to the fact that at high temperature some inclusions are formed such as MnS which when rolled will elongate in the direction of rolling refusing further breakdown [2]. This is detrimental to the properties of the material as such a high percentage of manganese, sulphur and other elements capable of forming such inclusions should not be allowed to exist concurrently. Fine grains are observed at this stage with an average ASTM grain size of 6.5; this shows the effectiveness of the restoration processes along the rolling sequence.

Figure 4 shows the structure of the final product with no much difference in the grain size from that of the intermediate sample only that the Widmanstaten ferrite now settles at prior austenite grain boundaries. An average ASTM grain size of 7 was also observed. 

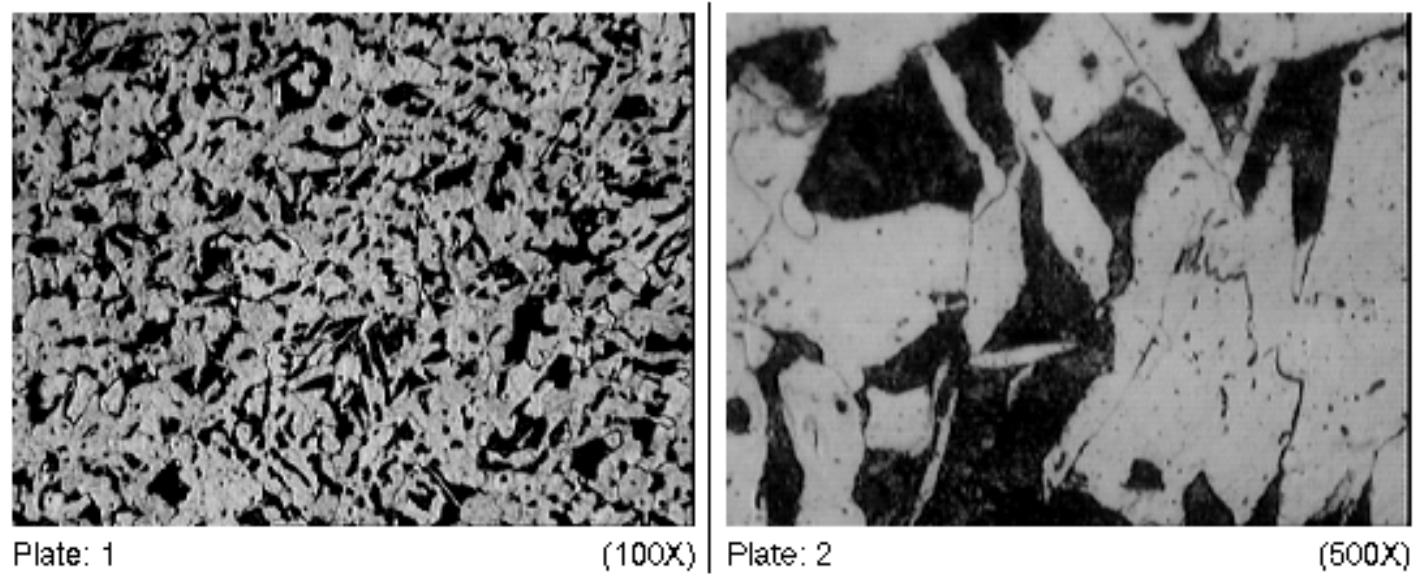

Figure 2: Microstructure of as cast material

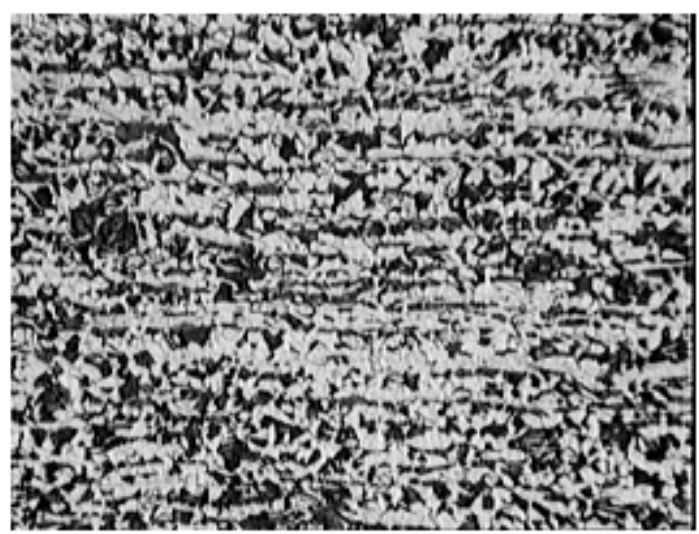

Plate: 1

(100x)

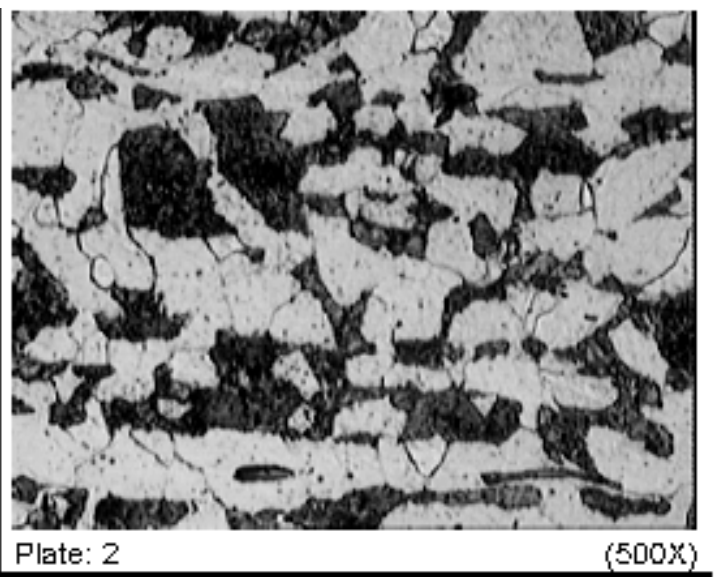

Figure 3: Microstructure of roughened material

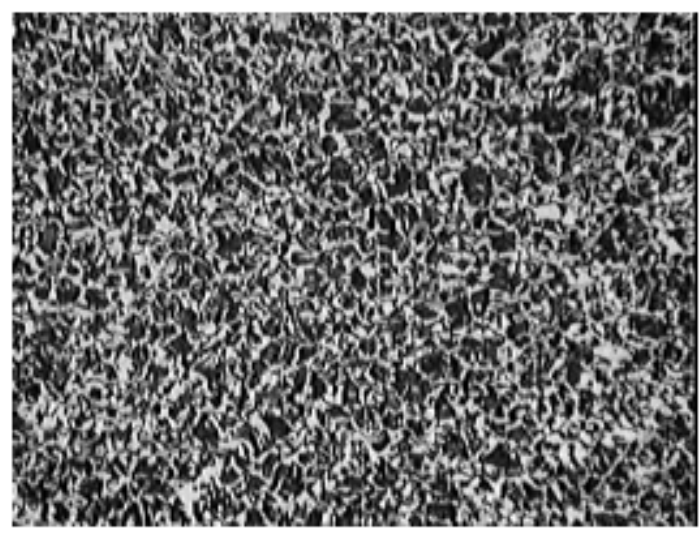

Plate: 1

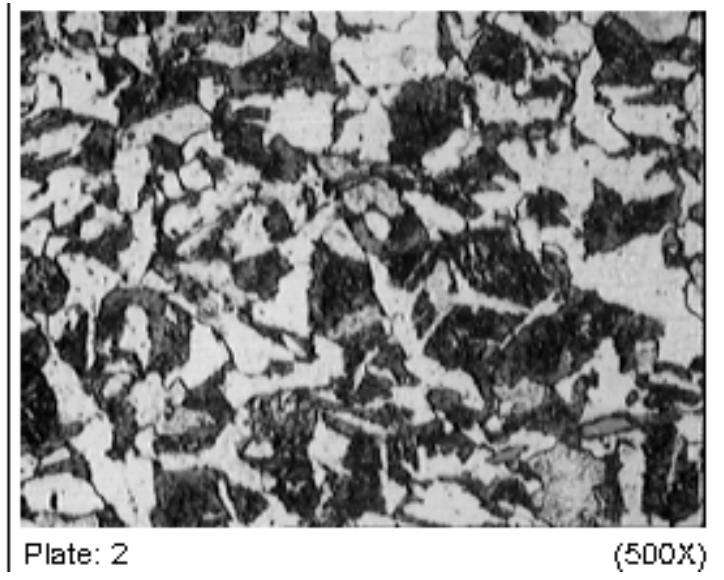

$(500 x)$

Figure 4: Microstructure of finished product 


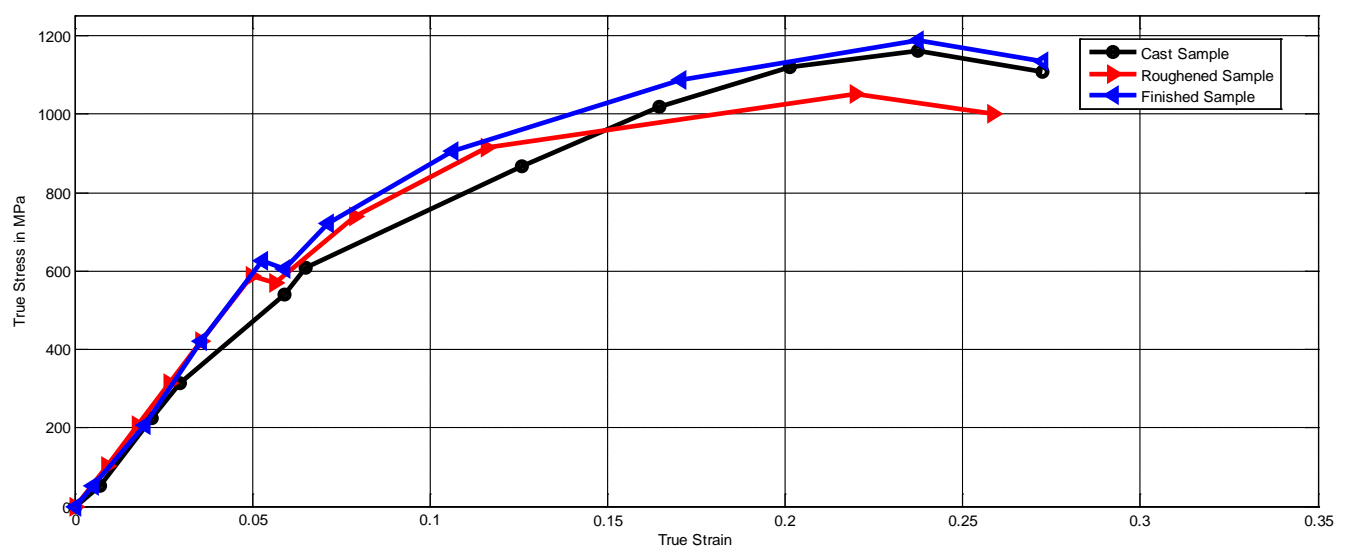

Figure 5: Stress Strain behavior of the three samples

Table 2:Summary of Properties of the three samples

\begin{tabular}{l|llllllll}
\hline & $\begin{array}{l}\mathrm{UTS} \\
(\mathrm{MPa})\end{array}$ & $\begin{array}{l}\text { Yield } \\
\text { strength(MPa) }\end{array}$ & $\begin{array}{l}\text { Fracture } \\
\text { strength(MPa) }\end{array}$ & $\begin{array}{l}\text { Ductilit } \\
\mathrm{y} \% \mathrm{EL}\end{array}$ & $\begin{array}{l}\text { Ductilit } \\
\mathrm{y} \% \mathrm{RA}\end{array}$ & $\begin{array}{l}\text { Pearlite } \\
\text { fraction }\end{array}$ & $\begin{array}{l}\text { Grain } \\
\text { size } \\
\left(\mathrm{d}^{-1 / 2}\right)\end{array}$ & $\begin{array}{l}\text { Hard } \\
\text { ness } \\
\text { RHC }\end{array}$ \\
\hline Cast & 916.59 & 580.507 & 1170.003 & 27.3 & 27.75 & 0.39 & 7.67 & 69.4 \\
Roughened & 845.3 & 560.139 & 2654.55 & 29 & 70.84 & 0.42 & 8.17 & 77.0 \\
Final & 936.95 & 595.784 & 2861.953 & 30.8 & 69.75 & 0.55 & 8.77 & $\begin{array}{l}106 . \\
0\end{array}$ \\
Product & 9 & & & & & & & \\
\hline
\end{tabular}

\subsection{Effect of Deformation Temperature and strain Rate}

Recovery and recrystallization are temperature dependent. The rate of recrystallization increases with increase in temperature. The combined effect of temperature and strain rate is accounted for in the Zener Hollomon Parameter which is the temperature compensated strain rate. The Zener Hollomon parameter is given by the equation [2];

$Z=\dot{\varepsilon} \exp \left(\frac{Q}{R T}\right)$

Where $\dot{\varepsilon}=$ Strain Rate

$T=$ Temperature

$R=$ Rate Constant

$Q=$ Activation Energy

The relationship between grain size and $\mathrm{Z}$ could be seen in the table below. The relationship is linear as shown in figure 6, resulting in a parametric equation of this kind; 
Table 3: Influence of $\mathrm{Z}$ on the grain size

\begin{tabular}{l|lll}
\hline & $\begin{array}{l}\text { Grain size } \\
\left(\mathrm{d}^{-1 / 2}\right)\end{array}$ & $\mathrm{Z}$ & InZ \\
\hline Cast & 7.67 & $2.117 \mathrm{E} 11$ & 26.08 \\
Roughened & 8.17 & $3.995 \mathrm{E} 12$ & 29.016 \\
Final Product & 8.77 & $2.336 \mathrm{E} 13$ & 30.738 \\
\hline
\end{tabular}

The constants a and b were determined to be 1.62 and 0.23 respectively

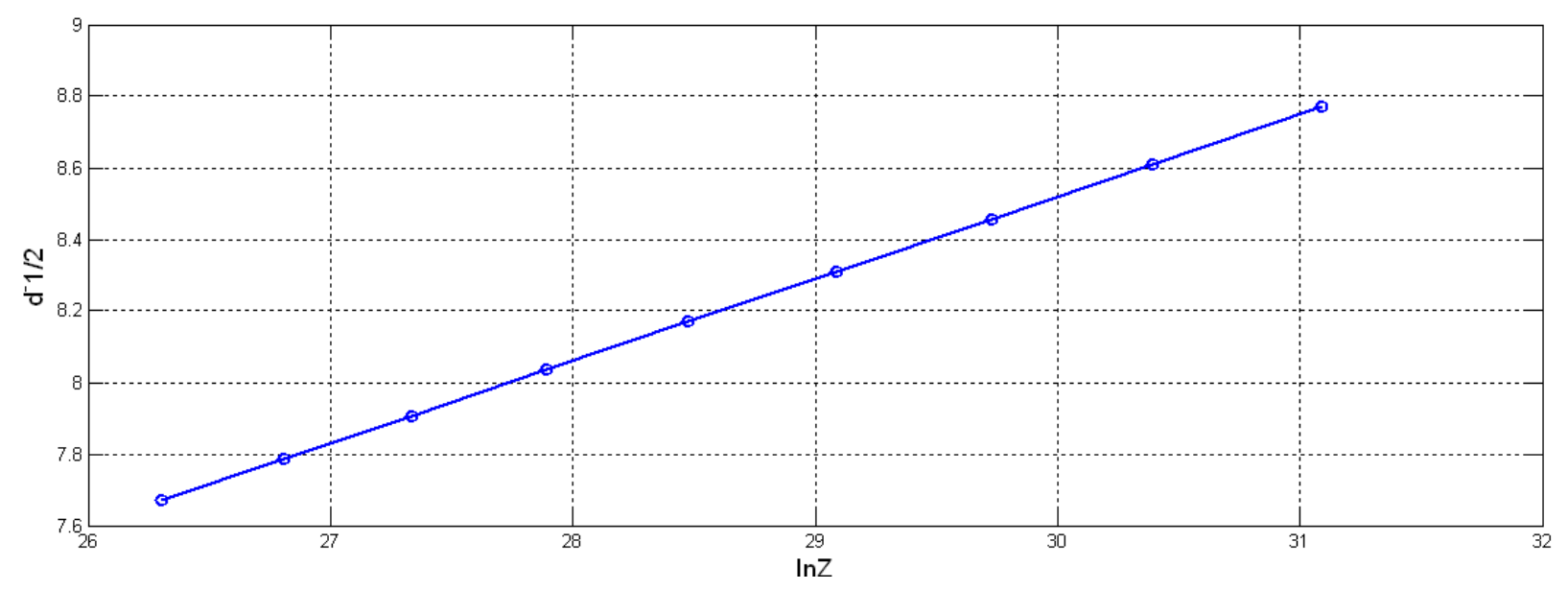

Figure 6: Effect of $\mathrm{Z}$ on grain size

\subsection{Structure Property Relationship}

A comparison of the properties of the three samples is shown in table 2. The tensile strength of the final rolled material measured by the ultimate tensile strength shows a $2.2 \%$ increase over that of the cast material and about $9.78 \%$ increase over that of the roughened material. The decrease in tensile strength of the roughened material with respect to the cast may be attributed to the presence of inclusions, moreover there is banding that may likely cause directionality in the tensile properties.This trend is also shown in the yield strength: about $2.6 \%$ increase in yield strength of the final rolled product is shown over that of the cast material. There is a marked increase in the fracture strength of the material along the process; this indicates the absence of inhomogenieties in the structure and the independence of fracture strength on banding. 
Ductility in terms of percentage reduction in area indicates a remarkable improvement. Over $150 \%$ increase in ductility of the roughened material relative to that of the cast material is seen. The same goes for that of the final rolled material. There is no marked difference between that of the roughened material and that of the final rolled product; this shows the dependence of ductility of grain size (fine grains favour ductility) and the distribution of pearlite in the microstructure.

Hardness is found to increases along the rolling sequence with a marked increase of over $27 \%$ between the final rolled product and the roughened material. This may be attributed to the distribution of pearlite. Pearlite distribution is a major determinant of hardness in steel; increase in pearlite distribution leads to increase in hardness.

The result shows that a combination of fine grain size, uniform distribution of phases and absence of inhomogenieties leads to a combination of high strength, hardness and ductility. This is evident in the final product where all the properties were highest. A lower strength was found in that of the roughened material due to the presence of inhomogenieties. Parameters that ensure the combination former results should always be used to ensure a better end product.

\section{CONCLUSION}

From the findings of this research work the following has been concluded;

The properties of a hot rolled material are dependent on the evolved structure, the evolved structure is a function of the restoration processes (recrystallization and recovery) taking place during the hot deformation which are in turn dependent on the structural parameters of the hot rolling process (temperature, strain, strain rate and Zener Hollomon parameter).

A combination of fine grain size, uniform distribution of phases and absence of inhomogenieties leads to a combination of high strength, hardness and ductility whereas inclusions affect strength adversely.

Grain refinement, uniform distribution of phases and proper dispersion of second phase particles are important consequences of the hot rolling process. 


\section{REFRENCES}

G. R. Gomez and T. Perez, Latin American Applied Research, 32(2002)253-256

I. Tanura “Thermomechanical Strengthening of High strength Low alloy Steels”, Butterworth UK, 1998

R. M. Forbes and L. Jackman, JOM, 51(1999):27-31

G. Zouhar, R. Kost and E Hirscwanner, supplkment au Journal de Physique 111, 3(1993): 11211127

M. Pietrzyk, supplkment au Journal de Physique 111, 3(1993): 1163-1171

L.A. Dobrzañski, A. Grajcar, W. Borek, International Scientific Journal, 37(2009):69-76

N. Wolańska, A.K. Lis, J. Lis, Journal of Achievements in Materials and Manufacturing Engineering20(2007):291-294 